\title{
Analyses on Personalized Employment Guidance in Higher Education
}

\author{
Liu Meng ${ }^{1, *}$
}

${ }^{1}$ Guilin Tourism University, Guilin, Guangxi 541006, China

* Corresponding Author: mengliufei@foxmail.com

(Received: 10/14/2019; Accepted: 09/23/2020; Published: 09/30/2020)

DOI: https://doi.org/10.37906/real.2020.8

\begin{abstract}
At present, with the development of entrepreneurship education, higher education draws more attention to students' learning processes and outcomes. Based on a scientific and standardized education system, entrepreneurship education requires higher education to provide students with more targeted, personalized, and flexible guidance to cater to their needs. Therefore, it is necessary to carry out personalized employment services and guidance. This paper aims to discuss how to provide personalized employment guidance and services according to the individual differences of students, and how to make the entrepreneurial education more diverse and get better results.
\end{abstract}

Keywords: Personalized Employment guidance; Higher education; Application; Entrepreneurship education

Institutions of higher education have been attaching more importance to entrepreneurship education. This has greatly improved the quality of teaching and learning. However, due to the changing environment of entrepreneurship trends and increasing social needs, the general standardized entrepreneurship education cannot meet the demand these days.

Therefore, broad methods of fully encompassed teaching that shifts the focus of instruction from the teacher to the student, personalized employment guidance and services have gradually developed.

What is personalized employment guidance and service? What role does it play in entrepreneurship education? How to apply personalized employment guidance and service in entrepreneurship education? These are important questions that need to be explored in detail.

\section{Personalized guidance and service are needed in entrepreneurship education}

Personalized guidance aims to provide customized guidance and service to comply with the individual differences of learners, thereby urging learners to move forward. Personalized employment guidance and service focus on delivering targeted and practical information, which inspires students to develop the creative thinking skills, knowledge, and attitudes necessary to help decide if it's the right choice for their future, especially when today's students face an uncertain future full of complex social issues. (Ding, 2012)

Not everyone fits into the rigidity of traditional corporate culture. In a nutshell, the application of personalized employment guidance and service will break the limits of traditional entrepreneurship education patterns, offering all-round services to meet the personal needs of college students.

1.1 The significance of promoting entrepreneurship education with personalized employment guidance 
People act differently because they perceive, parse, think, feel, want, need, react, and judge differently. Respecting these differences among college students by providing individualized employment guidance is the premise of entrepreneurship education. In addition, there are general skills that will be required regardless of the career you pursue.

In this way, personalized employment guidance aims to offer learners more targeted, comprehensive, meticulous, and systematic assistance, and it is useful to spend time understanding them, including their capabilities, expertise, and personal values.

Personalized employment guidance puts students' interests first; they can choose what they will learn, how they will improve their learning, and how they will assess their learning.

Personalized employment guidance not only respects students' differences and specific character traits but also facilitates the evaluation of their social adaptability and embraces their competitive advantage apart from learning to take more risks.

\subsection{The current situation and deficiencies researches in China}

In China, the development of entrepreneurship education has a short history that some colleges and universities only define. Thus, there remain many deficiencies in the explorations of personalized employment guidance.

\subsubsection{Higher education lacks objective and flexibility in promoting entrepreneurship education}

These days, more and more college graduates start their own business for their career plans. This not only benefits their ideas but also contributes to solving employment problems. Although Entrepreneurship education now caught the attention of the whole society and is popular in colleges and universities, higher education still adopts teaching or using social media as a key tool, so that concern on students themselves have become scarcer.

At the same time, entrepreneurship education without personalized employment guidance cannot acknowledge the student voice as central to their learning experience. Although we can follow the same process, career planning outcomes must be individualized.

\subsubsection{Sustainable development of entrepreneurship education lacks autonomy and independence}

In entrepreneurship education, students are short of enthusiasm to take part in practical activities. However, personalized employment helps to develop an entrepreneurial mindset and crucial life skills, which aims to develop learner autonomy and self-reliance by putting responsibility for the learning path in the hands of students. (Lai, 2012)

The outcomes of entrepreneurship will be flawed without fully student-oriented guidance. For example, if those with an entrepreneurial desire but lacking personal service, they shall be aimless and do not know how to start a business.

\subsubsection{Entrepreneurship education without personal pursuit is not popular}

Higher education will stay charming with complete hardware and standardized teaching programs to insure excellent education. Personalized employment guidance and service is icing on the cake which satisfies students' special needs and pleases them. Personalized employment guidance and service encourages creativity, innovation, and collaboration. (Long \& Wang, 2012)

1.2.4 Without personalized guidance and followed-up support cannot keep the integrity of entrepreneurship education 
Higher education has not closely combined theory with practice yet. Lacking personalized guidance and support cannot keep the integrity of entrepreneurship education. For instance, if entrepreneurship guidance lacks professional legal assistance such as contract review, professional consultation, enterprise bottleneck guidance, etc., the rights and interests of students cannot be protected. (Ding H. , 2010)

\subsection{Personalized employment guidance enlarges the range of entrepreneurship education}

To some extent, personalized employment guidance promotes the development of entrepreneurship education in many ways for students in college.

\subsubsection{Personalized employment guidance helps career planning}

Successful career planning is of great significance for college students to establish a correct career development concept. The career planning process is ongoing and sequential, focusing attention on work tasks and work environments.

Successful career planning is of great significance to college students' career selection and lifelong development. It can help college students establish a correct outlook on career development, objectively conducting self-analyses and career analyses, correctly grasp the employment situation, drastically understand the job market and social needs, establish career goals as early as possible, and scientifically formulate career plans.

\subsubsection{Making the transition from employee to entrepreneur}

Traditionally, graduates tend to favor jobs with a steady income which makes state-owned enterprises and institutions play a leading role in the employment market in China. In practice, some potential adventurous jobs are difficult to be chosen. It is time to change minds from employee to entrepreneur through personalized employment guidance. For those who desire to start their own business, personalized guidance prepares them to be responsible and enterprising individuals. It helps the student develop their grit, self-cultivation, innovation, team professional dedication, and they stand to ultimately gain the most from it.

\subsubsection{Strengthen entrepreneurship training for graduates}

As standardized testing has become more common in public schools, college students are generally unable to deal with financial management, marketing awareness, and communication skills. They have little knowledge of relevant policies and regulations, and they lack the psychological qualities needed to cope with economic and social changes.

Moreover, it is believed that employment is more stable than entrepreneurship, which leads university graduates to lack the confidence to face and overcome difficulties. Therefore, personalized employment guidance should possess targeted training to break down these stereotypes.

In addition to constructing a more reasonable and scientific entrepreneurship education curriculum programs, personalized employment guidance can also be directed to these students through ways such as second classrooms and community activities to cultivate their innovative ability and improve their entrepreneurial ability.

\subsubsection{Deliver career counseling for college graduates}

In personalized employment guidance, career counseling is a frequently used way designed to help students with choosing, changing, or leaving a career and is available at any stage in life. It can be offered either oral or written, and by answering questions via government presentations or networks of higher education. There are things we can do very easily that will help students reshape their self-awareness. 
The questions asked by entrepreneurs should be in line with the actual needs, as the strategy of policies and measures, business plan, and psychological consultation. Additionally, using tests to assess career possibilities, students will be better to make their career plans following the results with their interests and abilities. Thus, stop postponing and boost your career today.

In practice, a good tutor is also expected to provide targeted career counseling independently and continuously.

\section{How to apply personalized employment guidance in entrepreneurship education}

\subsection{Clarifying the confusion, misunderstanding and making points clear}

College students should clarify the confusions or misunderstandings existing in personalized employment guidance, and then make their points clear.

\subsubsection{Personalized employment guidance is an all-round entrepreneurship process}

It is generally considered that the personalized employment guidance service is designed for a certain stage. It takes each student's individuation into consideration and one-to-one guidance is more specific. Overall, personalized employment guidance allows the whole entrepreneurship process to be mature and completed.

\subsubsection{Personalized employment guidance is not separated from school teaching}

Based on professional knowledge and vocational skills which students should be learning during their four-year study, personalized employment guidance expands the fields and visions of students and serves them well beyond the classroom. Personalized employment guidance is not separated from school teaching.

\subsubsection{Personalized employment guidance is only available for certain students}

There is a misunderstanding that personalized services are specially provided for certain students, such as student cadres and students with entrepreneurial funds. This kind of misunderstanding will lead to our education not being treated equally and make many students lose confidence.

Our entrepreneurship education is carried out for all students. Personalized service is set up for students of different groups with different needs. It is provided for every student who receives entrepreneurship education.

\subsection{Concentrate on your entrepreneurship goals and characteristics}

College students should concentrate on life goals and characteristics of entrepreneurship education.

2.2.1 The relationship between personalized employment guidance and entrepreneurship education

Higher education must be explicit as to why entrepreneurship education should incorporate personalized employment guidance and service. UNESCO puts forward the concept of "entrepreneurship education", and proposes that entrepreneurial ability is regarded as the "third passport" that people should master in the future. The entrepreneurial education should have the same status as academic and vocational education.

Personalized guidance and service provides college students with a full range of services and enhances their entrepreneurial mindset competitiveness. Let personalized employment guidance become the mark for the development of education. 


\subsubsection{Entrepreneurial characteristics}

The relationship of individualization, standardization, continuity, and universality of entrepreneurial characteristics

- Standardization and individualization: Based on Standardization, individualization help students get more choices to meet their unique business proposals.

- Individualization and continuity: According to individual differences, the guidance will be assigned to tutors by stages

Standardized service gradually develops into personalized services. With the improvement entrepreneurship education, more mature and scientific personalized services can be included in the scope of entrepreneurship education.

After exploration and practice, the standardized operation will be systematically formed to become one of the standards for entrepreneurship education.

\subsection{Application of personalized employment guidance and service in entrepreneurship Education}

College students should apply personalized employment guidance and service in practice in entrepreneurship education.

\subsubsection{To establish a high-quality and professional team of entrepreneurial tutors}

Tutors, who are supposed to be familiar with start-up knowledge and real-world skills, meanwhile, can satisfy the multiple needs of the students at different levels. Additionally, off-campus entrepreneurs should be employed as part-time teachers to carry out real activity workshops. A professional team of instructors is of vital importance to ensure effective guidance.

Team of start-up tutors includes three parts: (1) entrepreneurship courses. (2) Tutors of practical experience, entrepreneurship students. (3) Entrepreneurs, alumni, experts, etc.

\subsubsection{To implement personalized entrepreneurship education programs and teaching methods}

The personalized entrepreneurship education curriculum is intended to be more student-oriented, emphasizing targeted and scientific construction based on students' grades, majors, and their specific needs. It can adopt the "three-stage" education model. In the first year, the focus is on entrepreneurial awareness. During the second and the third year, the students accumulate professional knowledge and learn leadership skills. The final year is the key stage for the start-up.

At the same time, according to the needs of different majors, higher education can set up different targeted entrepreneurial courses. For example, in some majors with a high possibility of start-up, it is necessary to add courses for increasing their entrepreneurial skills, entrepreneurial experience, entrepreneurial practice, etc.

The application of personalized employment guidance can adopt the "dynamic balance" mode, that is, to introduce new knowledge through case teaching, and to construct the knowledge of entrepreneurship through theoretical teaching, entrepreneur lectures and entrepreneurship training camps. (Wu, 2006)

At the same time, personalized employment guidance and service should pay attention to three combinations as follows:

(1) the integration of the whole process and every stage, (2) the combination of classroom teaching and entrepreneurship training, (3) and the combination of school resources and social resources. Personalized service is accompanied by the whole process of student learning, and it is targeted at different stages and different stages of different majors, which helps to carry out an efficient start-up. 
At the same time, based on classroom teaching, higher education is supposed to thoroughly integrate teaching and activities in practice, which can combine theories and practice to motivate students in their start-up. For example, organize events and programs, such as entrepreneurship training camps, SYB, entrepreneurship associations, etc.

Apart from taking advantage of on-campus resources, higher education can tap external resources actively, such as local resources, entrepreneurial institutions, alumni associations, enterprises, and law firms. Providing students with practical support and platforms, policy and legal assistance, and other follow-up support, start-up truly rely on the social platform for entrepreneurship guidance and services.

\subsubsection{To build up a student entrepreneurship archive and concentrate on four aspects}

For those who need to pay special attention, it is necessary to build up archives via collecting and sorting out the data of student's information, family background, career development plan, entrepreneurial ability, and entrepreneurial conditions, etc. In practice, typical examples will be recorded and followed up as well. Even more, higher education can set up entrepreneurship studios on campus for students that enthusiastic business owners or teachers work together to get win-win success, importantly, to raise students' greatest potency. (Li, 2012)

Paying attention to the four aspects, which includes special requirements, special background, specific students, and special groups.

First, special requirements, which refer to the special needs, raised by students during the learning process, such as individual consultation, entrepreneurial motivation analysis, making a conscious effort to assess yourself, etc.

Second, the special background, which means some special backgrounds in the education process, such as the student has an existing family business or has a history of entrepreneurial failure, etc. These students need special attention and guidance.

Third, specific students, which refers to special objectives. For example, students with invention patents on hand, students who already have entrepreneurial funds, and students who give up their studies to set up their own business, etc. They need targeted measures to provide differentiated services.

Fourth, special groups, such as members of entrepreneurial associations, entrepreneurial training camp students, Start Your own Business (SYB) students, entrepreneurial studio staff, they need group attention and guidance.

These four aspects need colleges to provide appropriate personalized employment guidance with a system and a good environment of entrepreneurship.

\subsubsection{To carry out multiple entrepreneurial training and practice with different conditions}

Personalized employment guidance strengthens entrepreneurial training and real practice for students who are interested in entrepreneurship.

Firstly, colleges carry out entrepreneurship training such as KAB and SYB, using advanced international courses, scientific and interesting teaching methods. Secondly, for students who are interested in entrepreneurship, higher education can set up second-classes, start an entrepreneurial club and increase entrepreneurial activities to strengthen students' abilities. Thirdly, students can get more experiences from entrepreneurship training camps, entrepreneurial competitions, and entrepreneurial practice bases.

Moreover, colleges can cooperate with companies. One example is a 'seven-day exchange'; it will enable students to act as employees to learn. Personalized service not only respects individual differences but also assesses evaluations for college graduates. 
Students need to learn how to identify problems before they learn how to solve them. Entrepreneurship education teaches students to identify problems which they have never encountered before.

\subsubsection{One-on-one consulting service}

A professional team composed of teachers, tutors, entrepreneurs, lawyers, and others should be set up to provide consulting services for student entrepreneurs. It is being able to help students to deal with psychological matters and other specific problems. For instance, tutors can analyze the pros and cons and possibilities of students and ensure their entrepreneurial goals more explicit. Generally speaking, personalized guidance costs more but benefits a lot.

\subsubsection{To set up interactive platforms for counseling services online and offline}

After standardizing consulting services, higher education should tirelessly seek new methods. Personalized counseling services can adopt in many ways such as face-to-face, answering on the Internet, messages on a mobile phone, etc.

In addition to the establishment of entrepreneurship counseling guidance, various resources are needed, such as entrepreneurs, experts, alumni, etc.

Diversified guidance and services will enrich entrepreneurship education. It is flexible and creative.

In the era of information, higher education has established platforms to offer employment guidance and services for students by the network. However, personalized services are still missing or only take up for a small part.

The platform has potential that needs to be deeply explored, such as online entrepreneurship consultation, legal assistance, entrepreneur communication, etc. It is more convenient for students to get information quickly and accurately.

\section{The effect of personalized employment guidance integrated entrepreneurship education}

Using the methods above, personalized employment guidance and service will get good feedback and effect.

\subsection{Individual requirements}

College students have a wealth of insight, intelligence, and innovation to make the right choices for their career in a rapidly changing world, and entrepreneurship is just one of their choices. Personalized guidance attaches importance to student-oriented education and benefits by unlocking the hidden potential of students. This inspires them to become creative, inventive, and innovative.

\subsubsection{Self-cognition and awareness of entrepreneurship}

Personalized employment guidance and services can be more effective to help students improve their self-cognition and awareness of entrepreneurship. It helps students clearly judge their possibility for startup. Most students are objectively and rationally aware of their start-up potential.

\subsubsection{Reasonably choose the development path}

Some students have entrepreneurial dreams and their entrepreneurial dreams may accompany their entire careers. A series of scientific evaluation systems and individual services are applied to answer questions for students such as whether they have the capacity, and the possibility of success, etc. 
Thus, students are reasonably able to choose their career paths. Entrepreneurship is one of the special paths of employment, and personalized employment guidance and service help to grasp opportunities accurately and avoid mistakes as best it could.

\subsection{Career planning}

Improving students' entrepreneurship awareness and basic skills, personalized guidance combines resources with students' interests to start their own business.

\subsubsection{To find out potential students}

Potential students such as specific character traits, patented technology, and entrepreneurship skills can be found and followed easily with personalized guidance and service. Additionally, personalized guidance provides service specifically for those who have a strong desire for entrepreneurship, make full preparation and some students may have the ability but they are not clear in their career target. That is, students will be classified and recorded differently.

\subsubsection{Provide professional and detailed information to attract students}

Higher education should provide targeted information and give assistance to individuals and teams who already have entrepreneurial projects. What we do is to provide special nutrients for students to cultivate the seeds of entrepreneurship and enable entrepreneurship education to get better outcomes.

\subsubsection{Increase the success rate of entrepreneurship}

Personalized guidance enables qualified students or teams with the entrepreneurial capacity to get support by integrated resources on and off-campus. Higher education turns to help to establish relations with companies and successful alumni to provide support and learn to avoid entrepreneurial risks. Finally, it will increase the success rate of entrepreneurship.

\section{Case study: "Binye Milk Tea Shop" by Zheng Bin and Yu Ye}

Zheng Bin and Yu Ye performed well in an entrepreneurship course when they were freshmen.

Once, there was a lecture, and their passion attracted the attention of the entrepreneurial teacher team. Thus, they registered into the school's entrepreneurship student archive. Through counselling, they started their businesses through high school. Zheng started a business on the network and $\mathrm{Yu}$ is interested in catering. With entrepreneurial foundation, they still maintained a high entrepreneurial passion in college.

Therefore, the tutor team decided to provide them catering guidance by the appointed tutor. These two students looked forward to opening a milk tea shop on the walking street in the school, because they found out that the milk tea here tasted poor and sold at a high price. These two students have skills, so the instructor guides them to conduct market researches. They found that the milk tea shop had a good market. However, the walking street had been managed by a third party, so the shop rent was very high, but this had not stopped them from assessing the market.

They were recommended to the entrepreneurship training camp to improve their entrepreneurship skills and delivered the projects to the school's project incubator base for cultivation. They chose a restaurant located on the second floor of the teaching building of the School of Tourism Management, which could provide all-day drinks and simple lunches but lacked milk and tea. Therefore, they finally decided to open a milk and tea shop here.

Hence, the tutor guided them to set up plans to cooperate with the school, sought free or low rent. The reasons were as follows: 
Firstly, hot milk and tea drinks shop could be suitable for the bar. Secondly, there were more opportunities for other students to take part-time jobs. Next, their shop turned to set a good example for other entrepreneurial students and could be a model entrepreneurial unit. Furthermore, part profits would be donated to the school.

Their career plan was endorsed by school and the school paid the bills for shop decorations.

During the preparation for the shop, the school recommended them to participate in the SYB entrepreneurship training organized by the Human Resources and Social Security Administration. With better technical and financial support, they felt it was a timely opportunity to start their businesses more soberly, rationally, and methodically.

In their sophomore year, the 'Bin-ye milk tea', named after them, started the business. Due to good management, their small shop did a good business and soon recouped their investment cost. The shop also became a good place for many teachers and students to have leisure time.

In the third year, the milk tea shop met some twists and turns. Therefore, their instructor invited successful graduates for guidance and advertising support, which effectively avoided risks. At the graduation stage, one of them wanted to stay here, while the other preferred to go back to his hometown to start his own business. In the end, Zheng agreed to stay and expand its brand into a chain. Finally, their shop was popular both on and off campus. Yu returned hometown to start a business and kept a relationship with Zheng.

With personalized guidance, Zheng and Yu had gotten good results and led a group of students to get the chances to practice and learn. The economic and spiritual benefits created wealth for the school at the same time. In this way, entrepreneurship education was carried out in a specific, vivid, and effective way, which produced better entrepreneurs.

\section{Conclusion}

The application of personalized employment guidance and service effectively promotes entrepreneurship education

\subsection{Personalized employment guidance and service enable entrepreneurship education to be more effective}

The creation of an efficient and vibrant education system is critical. Personalized employment guidance enables students to participate in entrepreneurial practice and exert students' subjective initiative to set up their own business actively. It serves as a wake-up call for students to develop the skills, knowledge, and attitudes necessary to achieve the long-term goals they set out for themselves. (Cheng, 2010)

Chinese people always believe that attitude is altitude, then details determine success or failure, hence personalized employment guidance would be more attentive to detail when students seek assistance and guidance.

With personalized employment guidance and service in start-ups that grow and create values, students not only just become ready to change their life, but also, 4they become ready to create their futures.

4.2 Students-oriented entrepreneurship guidance makes entrepreneurship education tend to be more diversified, detailed and comprehensive

Compared to personalized entrepreneurship guidance, traditional education cannot offer impartial advice, guidance, and information to students following their own special needs, and neglect different 
conditions, such as capacities, preparations, and career desires when students launch out on their own. (Niu, 2009)

For instance, students with the family business or with entrepreneurship projects prefer to get promotion training systematically. Meanwhile, targeted guidance on feasibility analysis of a project should be covered timely.

To sum up, personalized guidance makes entrepreneurship education tend to be more diversified, detailed, and comprehensive. For example, some 90 s regard success as their dream comes true. In that case, personalized employment guidance and service establishes the relation between the individual and the opportunity.

4.3 Personalized entrepreneurship guidance turns to make full use of students' major and school resources, and also better for colleges to enhance reputation and professionalism.

To ensure the quality of education, higher education needs scientific and standardized teaching systems. Moreover, higher education needs to be unique. Personalized entrepreneurship guidance plays an important role in higher education, which attracts students through individualized services and guidance. This requires extraordinary personalized guidance and service, which meet the individual special needs of students in a way so that students will feel satisfied during their start-up.

For instance, some colleges carry out their entrepreneurship education in a simulated environment, which lets students set up their own business independently. When students acquired Industry and Commerce Business License, a simulated certification imitated by the school, it's time for students to start their own business on campus. For example, China Changzhou Institute of Textile Garment Technology, Hunan Vocational and Technical College, etc.

Furthermore, the Nanjing University of Economics, as a representative, set up two courses of "innovative thinking" and "Creative learning" based on the characteristics of socioeconomic subjects. It involves acquiring and developing transferable skills in a wide range of fields outside major and is for all students and remains popular all the time.

What's more, personalized employment guidance and service can also refer to projects provided by colleges with their personalities and unique business proposals. Besides, higher education teaches students to think outside the box and nurtures unconventional talents and creative thinking skills.

\subsection{Entrepreneurship projects manage to benefit the students and society}

Entrepreneurship education in colleges is a systematic project, which requires the combination of theories training, practical experience and follow-up services support after starting their own business.

Such as Xinjiang Agricultural Vocational and Technical College, which makes thousands of students participate in entrepreneurial awareness training. One hundred people attended entrepreneurial skills training, ultimately hatched out of ten mature entrepreneurial projects. It promotes entrepreneurial education in higher education.

Also, some colleges establish "entrepreneurship nursery" with the help of local governments. The government provides start-up capital support, sub-projects, practical training and whole-process guidance for college students who can enter the entrepreneurship nursery.

What is more, some colleges establish the "college students' employment and entrepreneurship legal service system". They cooperate with organizations such as law firms to provide legal assistance to college students and facilitate them to identify potential risks of entrepreneurship. In addition, it will help to bring 
their vision to fruition. Professional legal guidance provides services such as contract review, professional consulting, enterprise bottleneck guidance, and other services.

This series of personalized guidance and support services guarantees the continuity and integrity of entrepreneurship education, effectively promoted the incubation of entrepreneurship projects, benefited students and schools, and increase employment.

\section{References:}

Cheng, R. (2010). On the Ideological Education and Crisis Intervention of College Students' Employment Vulnerable Groups. Education Eploration, 6.

Ding, H. (2010). Anaalysis of Entrepreneurship Education Content and Practical Teaching Model in Higher Vocational Colleges. Journal of Nanjing Institute of Technology, 1.

Ding, Y. (2012). Research on Countermesures of Personalized Employment Guidance in Colleges and Universities. Chinese College Students' Employment, 4.

Lai, Q. (2012). Exploration of the Role of Student Workers in the Process of Entrepreneurship Education for College Students. Chinese College Students' Employment.

Li, R. (2012). Exploration and Practice of Entrepreneurship Education Model in Higher Vocational College.

Long , G., \& Wang, Y. (2012). Guidance on Career Chioce of Post-90s Collge Students. Chinese Collge Students' Employment, 12.

Niu, C. (2009). Research on Entrepreneurship Education in British Universities. Shanghai: Shanghai Xuelin Press.

Wu, J. (2006). Exploration of Entrepreneurship Educaion Model and Practice in Higher Vocational Colleges. Journal of Jiujiang Vocational and Technical College, 1. 